\title{
Writer's Cramp as a Manifestation of Cervical Demyelinating Lesions
}

\author{
Joong-Seok Kim ${ }^{\mathrm{a}}$ Tae-Ho Guak ${ }^{\mathrm{b}}$ Jae-Young Ahn ${ }^{\mathrm{a}}$ Yeong-In Kim ${ }^{\mathrm{a}}$ Tae-Won Kim ${ }^{\mathrm{a}}$ \\ Kwang-Soo Lee L $^{a}$ \\ ${ }^{a}$ Department of Neurology, The Catholic University of Korea, Seoul, and ${ }^{b}$ Department of Neurology, Riche Clinic, \\ Bundang, South Korea
}

Dear Sir,

Typical signs and symptoms of the initial manifestations of multiple sclerosis (MS) include: sensory disturbances, motor paresis, optic neuritis and eye motility disorders. Movement disorders occurring in association with MS are rare [1]. We report a patient with focal dystonia of the right hand, which occurred exclusively during writing or with similar motor activities, including playing the electric guitar. This is the first report suggesting that writer's cramp may be an initial manifestation of MS.

\section{Case}

A 24-year old man presented with a 1year history of right hand dystonia during writing. At the age of 23, he suffered a sudden onset of dystonia during a written examination. Since that time, the right hand developed abnormal 'cramping' whenever the patient wrote or played the electric guitar. He had no history of exposure to neuroleptic drugs prior to the onset of dystonia, or alcohol addiction, perinatal asphyxia, trauma, arterial hypertension or diabetes. His family history did not reveal any history of movement disorders or psychiatric diseases.

On examination, a very mild postural hand tremor was noted bilaterally during arm extension. The patient showed significant right hand dystonia exclusively during writing or similar motor activities, such as playing the electric guitar (online suppl. video, www.karger.com/ doi/10.1159/000102169). Sensory examination showed hypesthesia of the right hand, most likely corresponding to segments $\mathrm{C} 7$ and $\mathrm{C} 8$. The muscle tone was normal at rest. The deep tendon reflexes in both extremities were symmetric and normoactive. Slit-lamp examination excluded Kayser-Fleischer rings.

An initial MRI scan of the brain and cervical spine showed focal demyelinating lesions involving the periventricular white matter and spinal cord segments C6 and $\mathrm{C} 7$ (fig. 1a-c). The results of our routine investigations, including hematological and biochemical screening, autoimmune profile, and measurements of the serum ceruloplasmin and copper and urine copper levels, were all normal. The cerebrospinal fluid studies including oligoclonal band and myelin basic protein were also normal. In addition, electrophysiological studies did not demonstrate any abnormalities. Three months later follow-up MRI of the brain showed enhancing plaques at subcortical white matter areas (fig. 1d).

\section{Discussion}

Movement disorders, other than tremor, have only rarely been associated with MS. Among these disorders paroxysmal dystonia is the most common; however, other involuntary movements, including chorea, ballism, generalized dystonia, spasmodic torticollis, writer's cramp and palatal myoclonia, probably result from demyelination of areas of the brain related to motor modulation [1].

In most cases of writer's cramp, the cause remains unknown, leading to the diagnosis of primary or idiopathic dystonia. The secondary causes of writer's cramp include: Parkinson's disease, spinocerebellar degeneration, spinal muscular atrophy and MS [2]. As in our case, the absence of a family history of dystonia and the presence of clinical signs such as abrupt symptom onset and sensory deficits in $\mathrm{C} 7$ and $\mathrm{C} 8$ dermatomes suggested a secondary cause for the writer's cramp. In addition, examinations such as MRI can support the diagnosis of MS (according to the new diagnostic criteria by McDonald et al. [3]).

In our case, cervical spine MRI showed abnormal signals involving the spinal segments C6 andC7. Although the exact anatomic correlation for writer's cramp has not been established, a number of hypotheses have been offered to explain movement disorders in patients with cervical cord lesions [4-7]. These include altered sensory input (in particular proprioceptive pathways), abnormal processing of both input and output signals in the spinal interneurons and increased excitability of the spinal motor neurons. Disruption of the somatosensory pathways or motor cortex to the striatum also may produce abnormal movements without sensory loss.

\section{KARGER}

Fax +41613061234 E-Mail karger@karger.ch www.karger.com (c) 2007 S. Karger AG, Basel 0014-3022/07/0581-0054\$23.50/0

Accessible online at: www.karger.com/ene
Dr. Kwang-Soo Lee

Department of Neurology, Kangnam St. Mary's Hospita

505, Banpo-dong, Seocho-gu

Seoul 137-701 (South Korea)

Tel. +82 2590 2720, Fax +82 2599 9686, E-Mail ks1007@catholic.ac.kr 

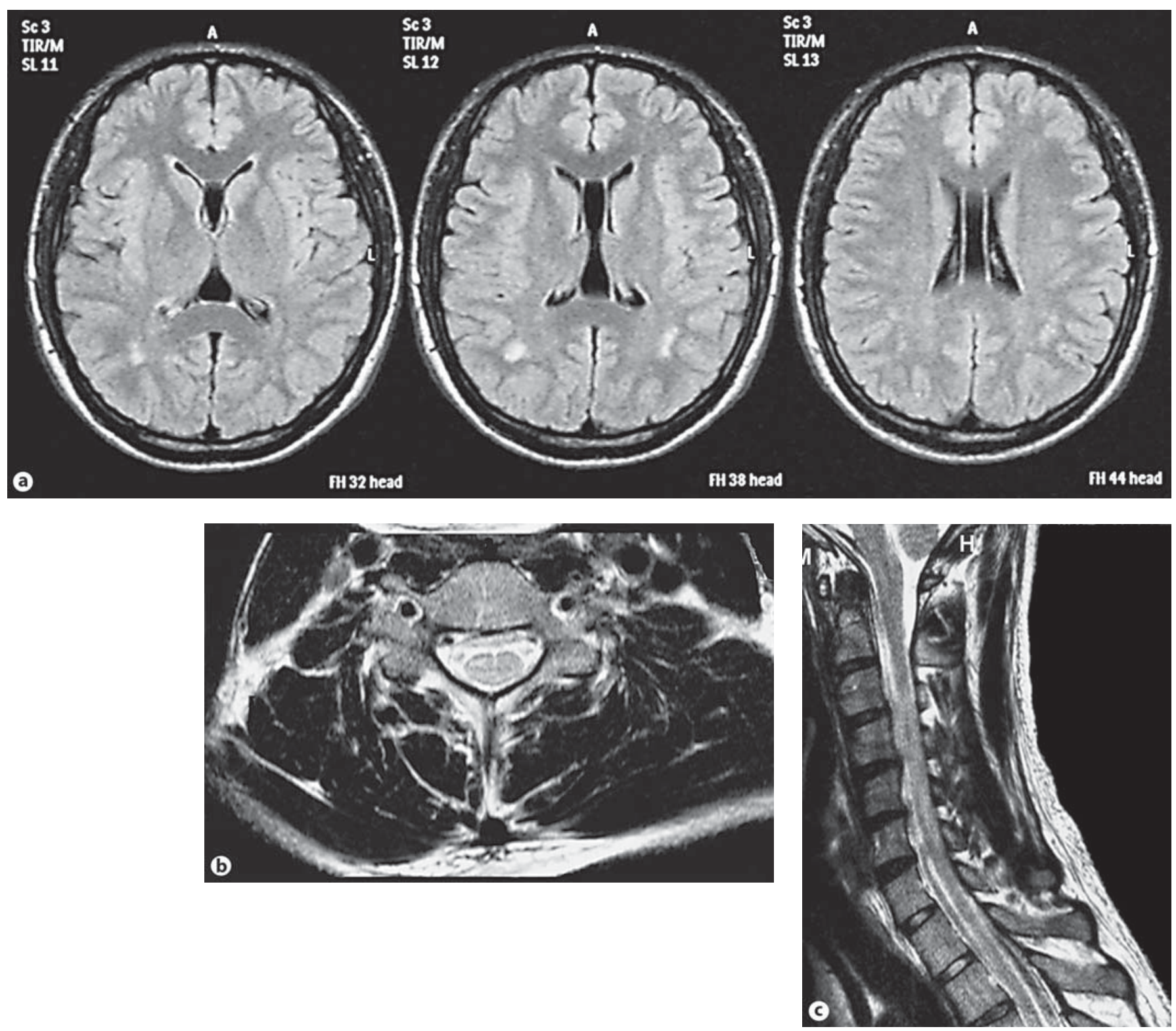

Fig. 1. MRI scans of the brain (a) and cervical spine (b, axial; c, sagittal) 1 year after clinical symptoms showed focal demyelinating lesions involving the periventricular white matter and spinal cord segments C6 and C7. Three months after, follow-up MRIs of the brain showed enhancing plaques at the subcortical white matter (d).

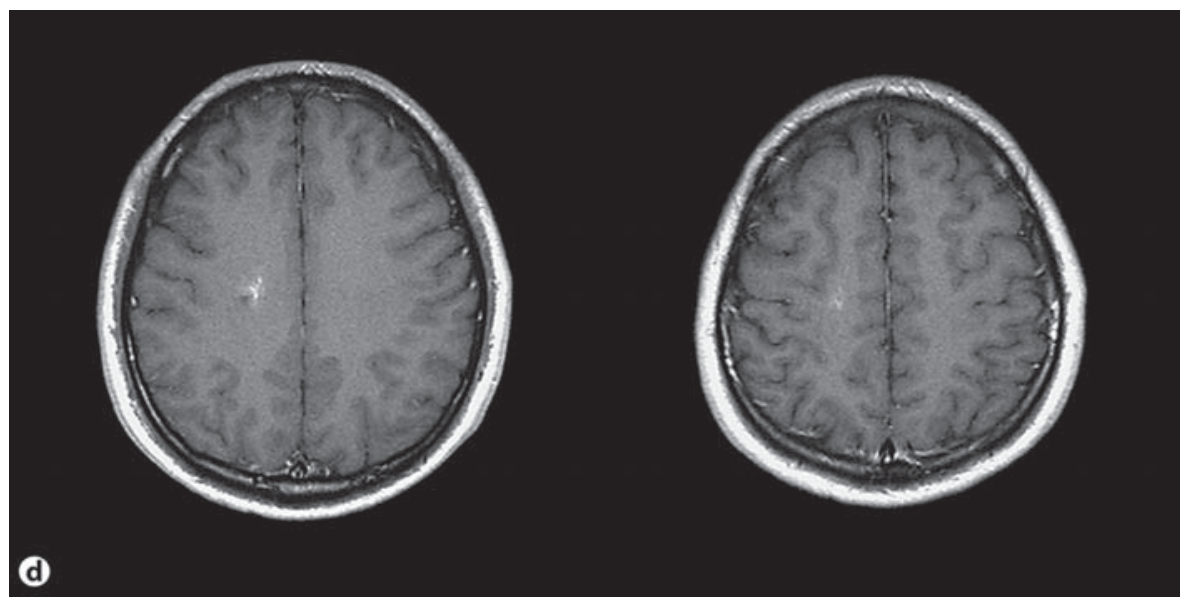

Writer's Cramp as a Manifestation of 
It is of course possible that writer's cramp is a coincidental finding in a patient with demyelinating lesions in the central nervous system. However, the probability of such a coincidence is extremely low according to the reported prevalence of MS in Korea of 2.36/100,000 [8] and of writer's cramp in Asia of 4.4/100,000 [9].

In conclusion, our findings suggest that alteration of central processing produced by MS likely explained the development of a task-specific dystonia in the present case. In addition, although there were no structural basal ganglia abnormalities on MRI, we speculate that subclinical basal ganglia dysfunction contributed to altered input and output signals at the cortical, subcortical or spinal levels, which may have been predisposing factors. Anecdotal reports have described focal dystonia resulting from different cervical lesions associated with spinal MS plaques [10-13]. However, writer's cramp was not the first manifestation of MS in any of these prior cases. This is the first report of writer's cramp occurring as the initial manifestation of MS, despite the absence of clinical and electrophysiological evidence of sensory abnormalities.

\section{References}

1 Tranchant C, Bhatia KP, Marsden CD: Movement disorders in multiple sclerosis. Mov Disord 1995;10:418-423.

2 Marsden CD, Sheehy MP: Writer's cramp. Trends Neurosci 1990;13:148-153.

3 Polman CH, Reingold SC, Edan G, Filippi M, Hartung HP, Kappos L, Lublin FD, Metz LM McFarland HF, O'Connor PW, SandbergWollheim M, Thompson AJ, Weinshenker BG, Wolinsky JS: Diagnostic criteria for multiple sclerosis: 2005 revisions to the 'McDonald Criteria'. Ann Neurol 2005;58:840846.

4 Sharp FR, Rando TA, Greenberg SA, Brown L, Sagar SM: Pseudochoreoathetosis: movements associated with loss of proprioception. Arch Neurol 1994;11:1103-1109.

5 Hill MD, Kumar R, Lozano A, Tator $\mathrm{CH}$, Ashby P, Lang AE: Syringomyelic dystonia and athetosis. Mov Disord 1999; 14:684688.

6 Ghika J, Bogousslavsky J: Spinal pseudoathetosis: a rare, forgotten syndrome, with a review of old and recent descriptions. Neurology 1997;49:432-437.

7 Nogues MA, Leiguarda RC, Rivero AD, Salvat F, Manes F: Involuntary movements and abnormal spontaneous EMG activity in syringomyelia and syringobulbia. Neurology 1999;52:823-834.
8 Lee SK, Roh JK, Kim KK, Lee SB, Myung HJ: Multiple sclerosis in Korea: its clinical features and estimated prevalence rate. J Korean Neurol Assoc 1989;7:218-228.

9 Fukuda H, Kusumi M, Nakashima K: Epidemiology of primary focal dystonias in the western area of Tottori prefecture in Japan: comparison with prevalence evaluated in 1993. Mov Disord 2006;21:1503-1506.

10 Madhusudanan M, Gracykutty M, Cherian M: Athetosis-dystonia in intramedullary lesions of spinal cord. Acta Neurol Scand 1995; 92:308-312.

11 Yucesan C, Tuncel D, Akbostanci MC, Yucemen N, Mutluer N: Hemidystonia secondary to cervical demyelinating lesions. Eur J Neurol 2000;7:563-566.

12 Uncini A, Di Muzio A, Thomas A, Lugaresi A, Gambi D: Hand dystonia secondary to cervical demyelinating lesion. Acta Neurol Scand 1994;90:51-55.

13 Klostermann W, Vieregge P, Kompf D: Spasmodic torticollis in multiple sclerosis: significance of an upper cervical spinal cord lesion. Mov Disord 1993;8:234-236. 